\title{
$\mathrm{PH} 105$
}

\section{La incorporación de las TIC y el patrimonio cultural en la escuela confirma su éxito para el fomento de la lectura}

¿Qué saben los niños del pueblo en el que están? De su historia, de la gente que un día hizo algo por él, de dónde viene su nombre... En la escuela pública rural de Pinos del Valle (El Pinar, Granada) ahora saben mucho más sobre el lugar donde viven. Gracias al proyecto Libros de nuestras historias, primer premio en 2021 de la III edición del certamen Enseñamos a leer. Una idea, de aplicación en el curso 20212022, que se presenta como una forma colaborativa de recuperación de la memoria colectiva, conectando el patrimonio local con el aprendizaje y el desarrollo de la lectoescritura; en definitiva, vinculando la escuela con su entorno.

Juan Félix García Pérez | Director del CPR El Pinar

URL de la contribución <http://www.iaph.es/revistaph/index.php/revistaph/article/view/5056>

El proyecto Libros de nuestras historias, diseñado para el alumnado del CPR El Pinar en la provincia de Granada, ha sido el ganador del III Certamen Enseñamos a Leer (2021) que promueve ideas innovadoras para el fomento de la lectura, y es organizado por La Universidad Internacional de Valencia (VIU) y la Fundación José Manuel Lara (FJML).

La idea principal de este trabajo es el fomento de la lectura, al mismo tiempo que la recuperación del patrimonio cultural de la localidad: una educación sobre y a través del patrimonio. Se trata del diseño de unas actividades que permiten al alumnado la experimentación y el análisis para adquirir conocimientos, interiorizar diferentes capacidades cognitivas, así como alcanzar competencias relacionadas con la recuperación y el mantenimiento del patrimonio cultural.

La localidad de Pinos del Valle compone, junto a las de Ízbor y Tablate, el municipio de El Pinar, integrado en la comarca del Valle de Lecrín (Granada). Dicho valle comienza en el inmemorial puerto del Suspiro del Moro $y$, desde allí, desciende hasta las angosturas de Ízbor, desde donde se atisba la inmediatez de las orillas del Mediterráneo. Está, por tanto, al sur de Granada, que diría Gerald Brenan, ocupando el espacio entre Granada y la Alpujarra. Ha sido desde tiempos remotos una zona de tránsito entre la ciudad y la costa y, quizá por eso,

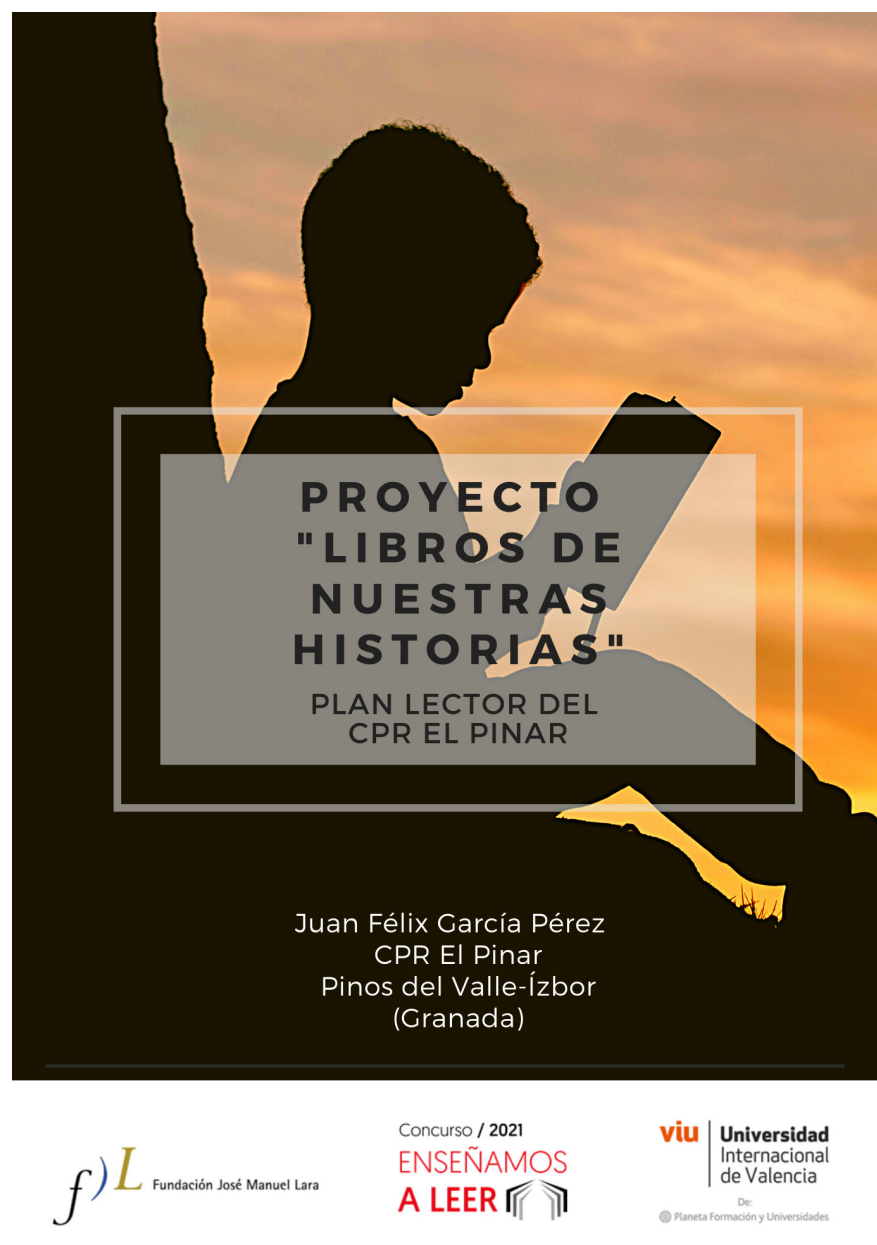

Portada del proyecto, de aplicación en el curso 2021-2022 

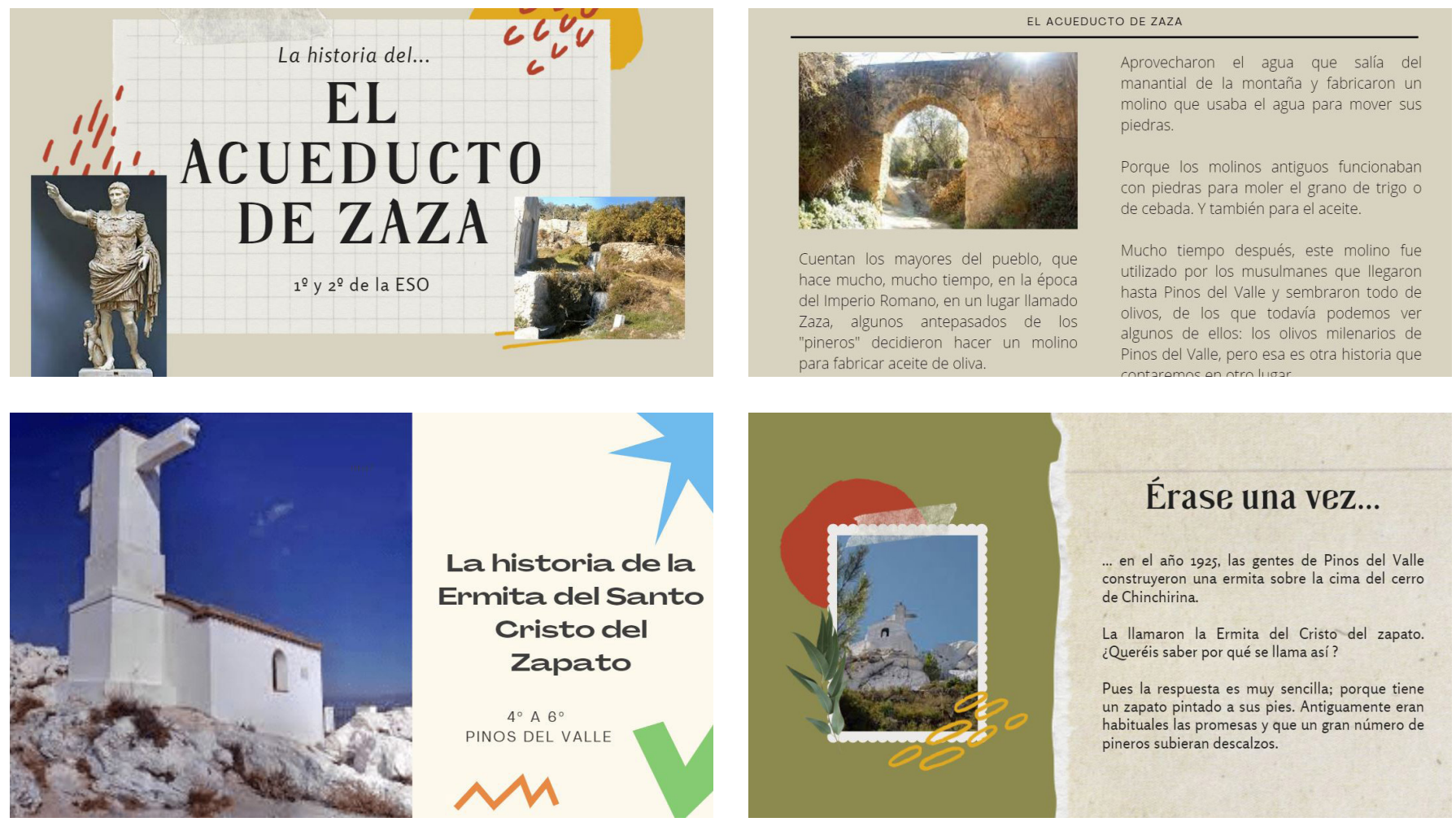

Trabajos que ya están comenzando a diseñar los grupos de $1^{\circ}$ y $2^{\circ}$ de la ESO y de $4^{\circ}$ a $6^{\circ}$ de Primaria sobre dos temáticas emblemáticas de la localidad

en el siglo XXI, se ve abocada a una despoblación lenta pero inexorable, una hemorragia de gentes que se van, en todos los sentidos: se marchan los jóvenes de estos lugares del Valle de Lecrín en busca de una nueva vida, incluso mejor. Pero vuelven. Regresan a ver a sus familiares. También se marchan los mayores, lentamente, sin apenas hacerlo notar, y con ellos se llevan sus recuerdos, su sabiduría y no vuelven. Cada vez que desaparece una persona mayor, el océano del olvido que supone el paso del tiempo ocupa más espacio entre las personas que vivieron con ella; hasta que ya no quede nadie que recuerde cómo era la vida, cuáles fueron las historias que les apasionaban y que dotaron de identidad propia a las personas.

El patrimonio cultural de Pinos del Valle, en particular, y de la comarca del Valle de Lecrín, en general, es un rico mosaico de expresiones culturales de aquellas generaciones que nos antecedieron en el que se incluyen obras literarias, tradiciones orales, músicas, yacimientos naturales y arqueológicos. Desde nuestro centro educativo, pretendemos hacer uso de estos recursos para que sirvan de hilo conductor y permitan acercar temas motivantes para el aprendizaje del alumnado y, al mismo tiempo, salvar su tradición del olvido.

Independientemente del enfoque educativo que supone la utilización del patrimonio cultural para que nuestro alumnado se motive hacia la lectura, consideramos que es imprescindible introducir la cultura y las tradiciones rurales a las nuevas generaciones. Máxime, cuando dicha inserción se plantea en nuestras aulas a través del uso de herramientas TIC. Desde esta perspectiva, buscamos que nuestro alumnado desarrolle competencias digitales vinculadas a la recuperación y pervivencia de su pasado. Para ello utilizan en clase diferentes aplicaciones y programas informáticos que aportan un formato actual a las historias de antes.

Narraciones como El Cristo del zapato de Pinos del Valle, La Cueva del Negro, La Cueva del Búho, El Ojo Oscuro, entre otras muchas, retoman, cada vez que se 


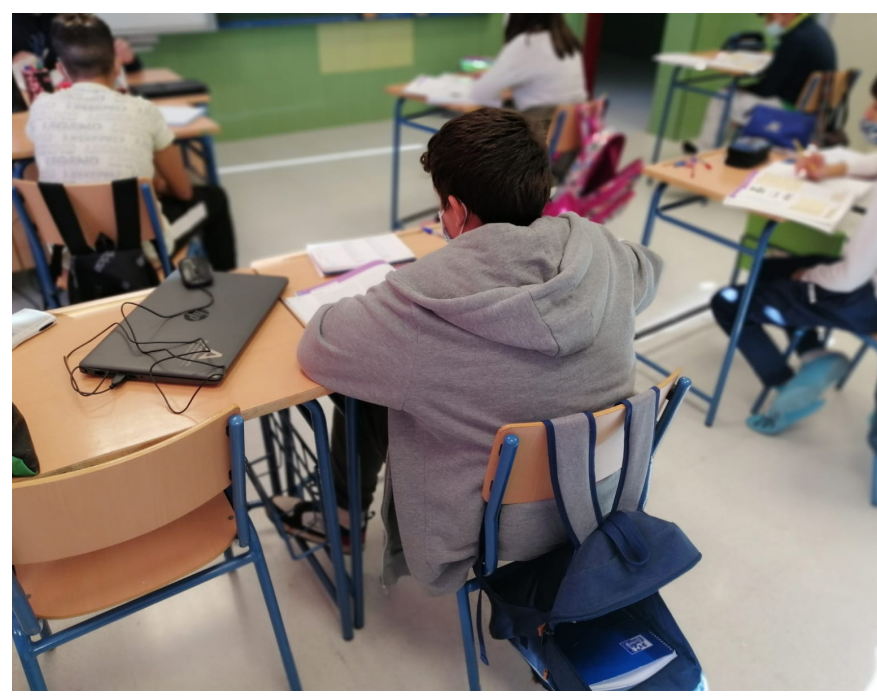

Alumnado del CPR El Pinar (grupo internivel de $1^{\circ}$ y $2^{\circ}$ de la ESO) trabajando aspectos relacionados con la revisión de textos | fotos proyecto Libros de nuestras historias

cuentan, una tradición que no debe perderse. Para ello, se desarrolla una biblioteca, cuyos ejemplares elaboran los propios alumnos en diversos soportes, tanto digitales como físicos, a través de los cuales podemos acercar, gracias a la magia de las palabras, las historias de nuestros antepasados. De igual forma que en la antigua biblioteca de Alejandría, aquella que ideó Ptolomeo I a comienzos del siglo III a. de C., donde se recopiló todo el saber de la antigüedad (o al menos eso pretendía), queremos convertir nuestro centro en el generador y recuperador de tradiciones de la localidad y de toda la comarca.

Adaptando las actividades a las características del alumnado que las lleva a cabo, se crean cómics, pequeños libros digitales y vídeo cuentos que se irán subiendo a la página web del centro, ofreciendo así la posibilidad de acceder a todas aquellas personas que estén interesadas. Pretendemos de esta forma contribuir al fomento de una sociedad del conocimiento compartido. El patrimonio cultural local pasa así a formar parte del plan de estudios de nuestra escuela desde un enfoque multidisciplinar. No solamente se aborda desde el área de ciencias sociales en la etapa de Educación Primaria, o desde la asignatura de Historia en la etapa de ESO, es un proyecto interdisciplinar que abarca la totalidad de materias que se trabajan.
Nuestro alumnado debe aprender la necesidad de identificar, preservar, recuperar y compartir conocimientos preservando la memoria colectiva. Y para ello, desde la escuela coordinamos un trabajo en el que las familias transmiten las historias a los alumnos y alumnas y las traen al colegio. Las aulas se convierten en laboratorios $y$, el alumnado, en alquimistas que extraen los elixires del pasado y les dan formas nuevas, más acordes a los tiempos actuales. Pero lo más importante es que con su quehacer en clase rescatan del olvido su herencia cultural, la ponen al día y además contribuyen a su difusión hacia quienes no poseen lazos con estas tierras ni sus gentes.

Convertimos a nuestro centro en un ente que, además de formar y educar a nuestro alumnado, genera recursos patrimoniales para la comunidad de Pinos del Valle y de quienes llegan hasta allí. Se proporciona un servicio a la comunidad, utilizando metodologías muy eficaces para el aprendizaje ya que permiten a los docentes y al alumnado implementar unas prácticas que dotan de sentido y de utilidad a la realidad que se aborda en las aulas. Aprenden a ser competentes siendo de utilidad a los demás. 